\title{
Rates and Indications of Cesarean Section Using the Robson Classification in a University Hospital in Southern Thailand 2014-2016
}

Jarawee Sukmanee, M.D. ${ }^{1}$, Tippawan Liabsuetrakul, M.D., Ph.D. ${ }^{1,2}$, Krantarat Peeyananjarassri, M.D. ${ }^{2}$

${ }^{1}$ Epidemiology Unit, Faculty of Medicine, Prince of Songkla University, Hat Yai, Songkhla 90110, Thailand.

${ }^{2}$ Department of Obstetrics and Gynecology, Faculty of Medicine, Prince of Songkla University, Hat Yai, Songkhla 90110, Thailand. Received 29 February $2020 \bullet$ Revised 13 April $2020 \bullet$ Accepted 14 April $2020 \bullet$ Published online 1 July 2020

\section{Abstract:}

Objective: To identify the rates and indications of cesarean section (CS) using the Robson classification during 20142016 in a university hospital in southern Thailand.

Material and Methods: A cross-sectional study of women who delivered between January 1, 2014 and December 31, 2016 was conducted. The data were analyzed using the Robson classification.

Results: A total of 10,474 births were included in the analysis. The overall CS rate was 55.5\%. The trends of CS rates in most Robson classification groups over the 3-year period were static. The CS rates in nulliparous or multiparous women with induction of labor decreased over the 3-year period, while the rate in multiparous women with fetal breech presentation increased. Women with previous cesarean section (Robson group 5) were the largest contributor to the overall CS rate $(32.1 \%)$, followed by the nulliparous women with a single cephalic pregnancy, $\geq 37$ weeks gestation in spontaneous labor (Robson group 1) (24.5\%). Cephalopelvic disproportion and fetal distress were the most common indications for CS in Robson group 1.

Conclusion: The CS rates in our study were high in all groups during the 3 -year period, with static trends in most groups. The Robson classification is a feasible tool for monitoring CS rates in our setting. Feedback of these findings to healthcare providers and policy makers is advised.

Keywords: cesarean section rate, indications, Robson classification, trend

Contact: Prof. Tippawan Liabsuetrakul, M.D., Ph.D.

Epidemiology Unit, Faculty of Medicine, Prince of Songkla University,

Hat Yai, Songkhla 90110, Thailand.

E-mail: Itippawa@yahoo.com

(c) 2020 JHSMR. Hosting by Prince of Songkla University. All rights reserved.

This is an open access article under the CC BY-NC-ND license

(http://www.jhsmr.org/index.php/jhsmr/about/editorialPolicies\#openAccessPolicy).
J Health Sci Med Res 2020;38(4):307-319 doi: $10.31584 /$ jhsmr.2020750 www.jhsmr.org 


\section{Introduction}

Cesarean section (CS) is an important obstetrics procedure to save maternal and fetal lives when vaginal birth is jeopardous. The World Health Organization (WHO) recommended that a regional CS rate should not exceed 10.0-15.0\%. ${ }^{1}$ Nevertheless, CS rates have been increasing worldwide over the past decade, especially in middleand high-income countries. ${ }^{2}$ According to WHO multicountry surveys, the overall world CS rate increased from $26.4 \%$ in $2004-2008$ to $31.2 \%$ in $2010-2011$. In Thailand, the CS rate also increased from $20.3 \%$ in 2005 to $32.7 \%$ in $2015 .^{2}$ Increasing CS rates not only increase the risk of maternal and neonatal morbidities but also have a negative impact on health expenditures and medical resources. ${ }^{3-5}$ Therefore, rising CS rates have become a major public health concern.

In order to understand this trend and to implement interventions to reduce unnecessary or increase indicated CSs, a monitoring system for CS rates in specific groups for both unnecessary and indicated CSs is needed. A systematic review in 2011 recommended that the Robson classification was the most suitable system for monitoring CS rates. ${ }^{6}$ The Robson CS system classifies pregnant women admitted for delivery into ten groups based on six obstetric characteristics, namely parity, previous CS, gestational age, onset of labor, number of neonates and fetal presentation at birth. $^{7}$ The Robson classification categories are mutually exclusive, totally inclusive and can be applied prospectively to give useful information and point to problem areas where remedial action might be most useful. ${ }^{6}$ In 2015, the WHO proposed the Robson classification as a global standard for analyzing and comparing CS rates across different hospitals, countries and regions. ${ }^{8}$

The Robson classification has been used to analyze CS rates in several countries, including a few studies from Thailand. ${ }^{9-12}$ Analyzing the CS rates in university hospitals is crucial because these hospitals require good clinical practice for appropriate use of CS and to provide a positive role model for medical students. The objectives of this study were to identify the trend and indications of CS using the Robson classification during 2014-2016 in the only university hospital in southern Thailand.

\section{Material and Methods}

A cross-sectional study was conducted during 1 February - 30 June 2018 at the only university hospital which is also the largest referral center in southern Thailand. This hospital has more than 3,000 births a year including many complicated obstetric cases. Obstetrics care provided to pregnant women in this public hospital is divided into either public or private services. For public service, women receive routine antenatal and delivery care by any obstetricians or training residents in charge on the day of services attended, while women in private service receive antenatal and delivery care by the same obstetrician agreed upon by the private service. All maternity services include either vaginal or CS births which are covered by the health insurance reimbursed to the hospital. In our hospital, the CS rate increased from $26.2 \%$ in 1990 to $55.1 \%$ in 2013.

The data of all women admitted for delivery in our hospital recorded in the database from 1 January 2014 to 31 December 2016 were included in the analysis.

All variables which are used in the Robson classification system were available in the database of the Statistical Unit except for onset of labor, which data were additionally retrieved from the delivery logbook and/or medical records in the Hospital Information System.

Variables for the Robson classification are previous CS (yes or no), parity (nulliparous or multiparous), gestational age at birth (preterm $<37$ weeks or term $\geq 37$ weeks), 
onset of labor (spontaneous, induced or no labor), number of neonates (single or multiple), and presentation at birth (cephalic, breech or transverse). Gestational age recorded in the database was estimated by the last menstrual period or the first ultrasound measurement as available. ${ }^{13}$ The Robson classifications based on the various combinations of these characteristics are shown in Table $1^{7}$

The outcome variables of the study were mode of birth and indications for CS. Mode of birth was classified as CS or non-CS. Indications for CS were as diagnosed by the obstetricians and recorded in the hospital database. Failed induction was defined as the inability to achieve the active phase of labor after prostaglandin administration and/or amniotomy or oxytocin infusion in case of labor induction. ${ }^{14}$ The diagnostic criteria for cephalopelvic disproportion in our hospital were (1) at least $3 \mathrm{~cm}$ of cervical dilatation and $80.0 \%$ of effacement, (2) good uterine contraction for at least 2 hours, and (3) diagnosis of arrest/protraction of labor or prolonged second stage. ${ }^{15}$ Low birth weight was defined as birth weight $<2,500$ grams and birth asphyxia was defined as Apgar score at 1 minute $<7 .^{16}$

Independent variables and maternal characteristics included age (teenage pregnancy <20 years, 20-34 years or advanced maternal age $\geq 35$ years), pre-pregnancy body mass index (BMI, derived from weight in kilograms divided by the square of the height in meters), and service type (public or private).

The onset of labor data was merged with the database from the Statistical Unit. The data retrieved from the database were cleaned and corrected by reviewing the medical records if necessary. The data were analyzed using $R$ version 3.5.1. The Robson classification was analyzed as percentages in each group in terms of relative size, CS rate, absolute contribution, and relative contribution. ${ }^{17}$ Relative size was calculated by dividing the number of births in the group by total births. CS rate was calculated by dividing the number of cesarean births in the group by the number of births in the group. Absolute contribution was calculated by dividing the number of cesarean births by total births. Relative contribution was

Table 1 The Robson classification system

\begin{tabular}{ll}
\hline Group & Characteristics \\
\hline 1 & Nulliparous, single cephalic, $\geq 37$ weeks, in spontaneous labor \\
2 & Nulliparous, single cephalic, $\geq 37$ weeks, induced or CS before labor \\
2a: induced & 2b: CS before labor \\
& Multiparous (excluding previous CS), single cephalic, $\geq 37$ weeks, in spontaneous labor \\
3 & Multiparous (excluding previous CS), single cephalic, $\geq 37$ weeks induced or CS before labor \\
4 & 4a: induced \\
& 4b: CS before labor \\
& Previous CS, single cephalic, $\geq 37$ weeks \\
& All nulliparous breeches \\
7 & All multiparous breeches \\
8 & All multiple pregnancies (including previous CS) \\
9 & All abnormal lies (including previous CS) \\
10 & All single cephalic, <37 weeks (including previous CS)
\end{tabular}

$\mathrm{CS}=$ cesarean section 
calculated by dividing the number of cesarean births by total cesarean births. The Robson classification and maternal characteristics percentages were analyzed by year. The CS rates based on the Robson classification for public and private services were analyzed using chisquared test with Bonferroni correction for multiple comparisons.

The trends of CS rates in the various Robson groups during the 2014-2016 period were analyzed using chi-squared test with a significance level of $<0.05$. The top three indications for CS in the initially non-indicated groups were presented in stacked bar charts stratified by year. All graphics were created using the ggplot2 package.

The study was approved by the Institute Ethics Committee, Faculty of Medicine, Prince of Songkla University. Access to the databases was approved by the hospital director and the department committee of the Department of Obstetrics and Gynecology. Informed consent was waived because it was a retrospective medical records review.

\section{Results}

A total of 10,508 delivery records were obtained from the two hospital data sources of which 34 were excluded due to no delivery conditions (abortion, ectopic pregnancy or molar pregnancy), leaving the records of 10,474 women who gave birth during the study period included for analysis, 3,483, 3,609, and 3,381 from 2014 to 2016 , respectively (Figure 1). The characteristics of the study women are presented in Table 2. Both maternal age and BMI slightly increased during the 3-year period, while the proportion of women using public service, being nulliparous, and having spontaneous labor slightly decreased.

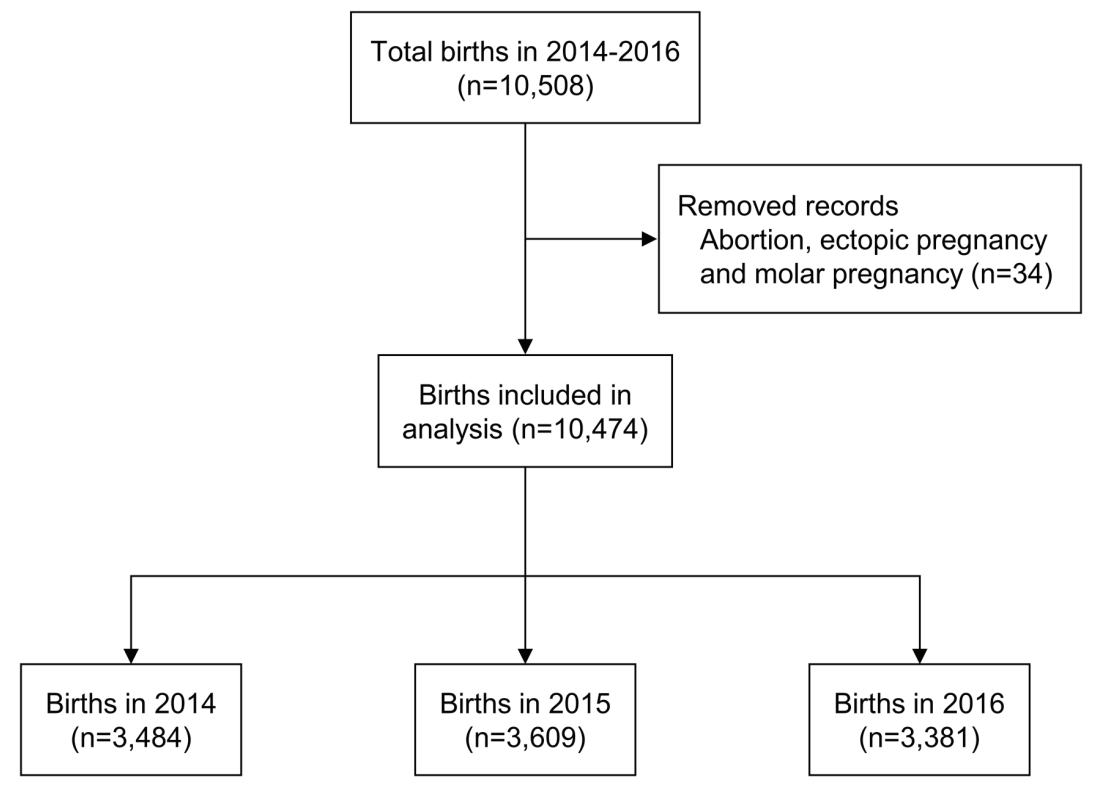

Figure 1 Flow chart of the selection of study participants 
Table 2 Characteristics of women giving birth during 2014-2016

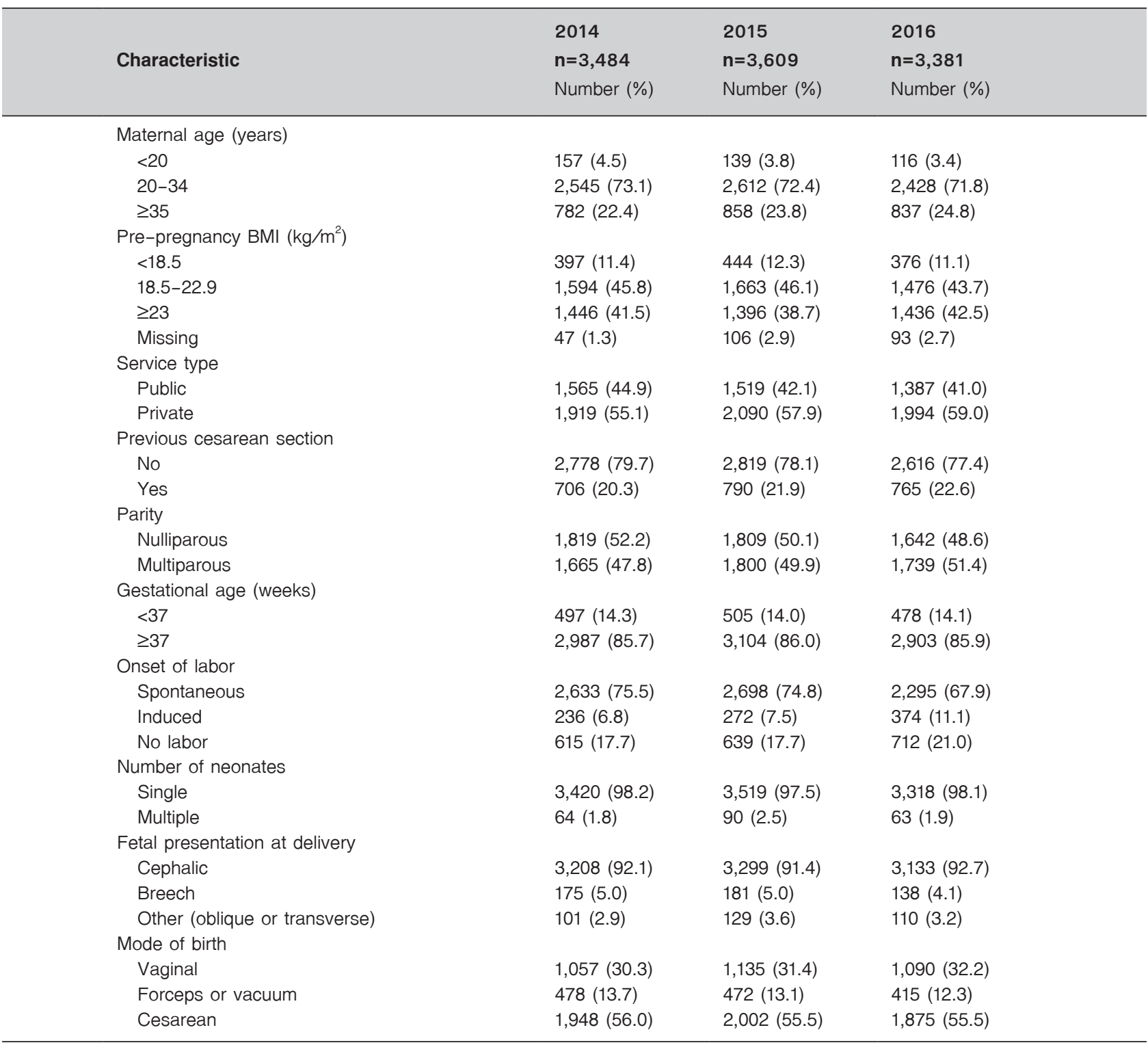

$\mathrm{BMI}=$ body mass index, $\mathrm{kg} / \mathrm{m}^{2}=\mathrm{kilogram}$ per square meter

Table 3 shows the CS rates classified into the Robson classifications during the study period. The women in Robson group 1 had the highest number of births, followed by groups 3 and 5 . Within the same group, CS rates of more than $50.0 \%$ were observed in all groups in all years, except in group 1 with rates of $42.4 \%, 40.9 \%$ and $40.0 \%$ and group 3 with rates of $16.6 \%, 14.0 \%$ and $10.5 \%$ in 2014, 2015 and 2016, respectively. In 2016, the relative and absolute contributions to the overall CS rates were highest in group 5 (33.9\% and $18.8 \%$, respectively), 


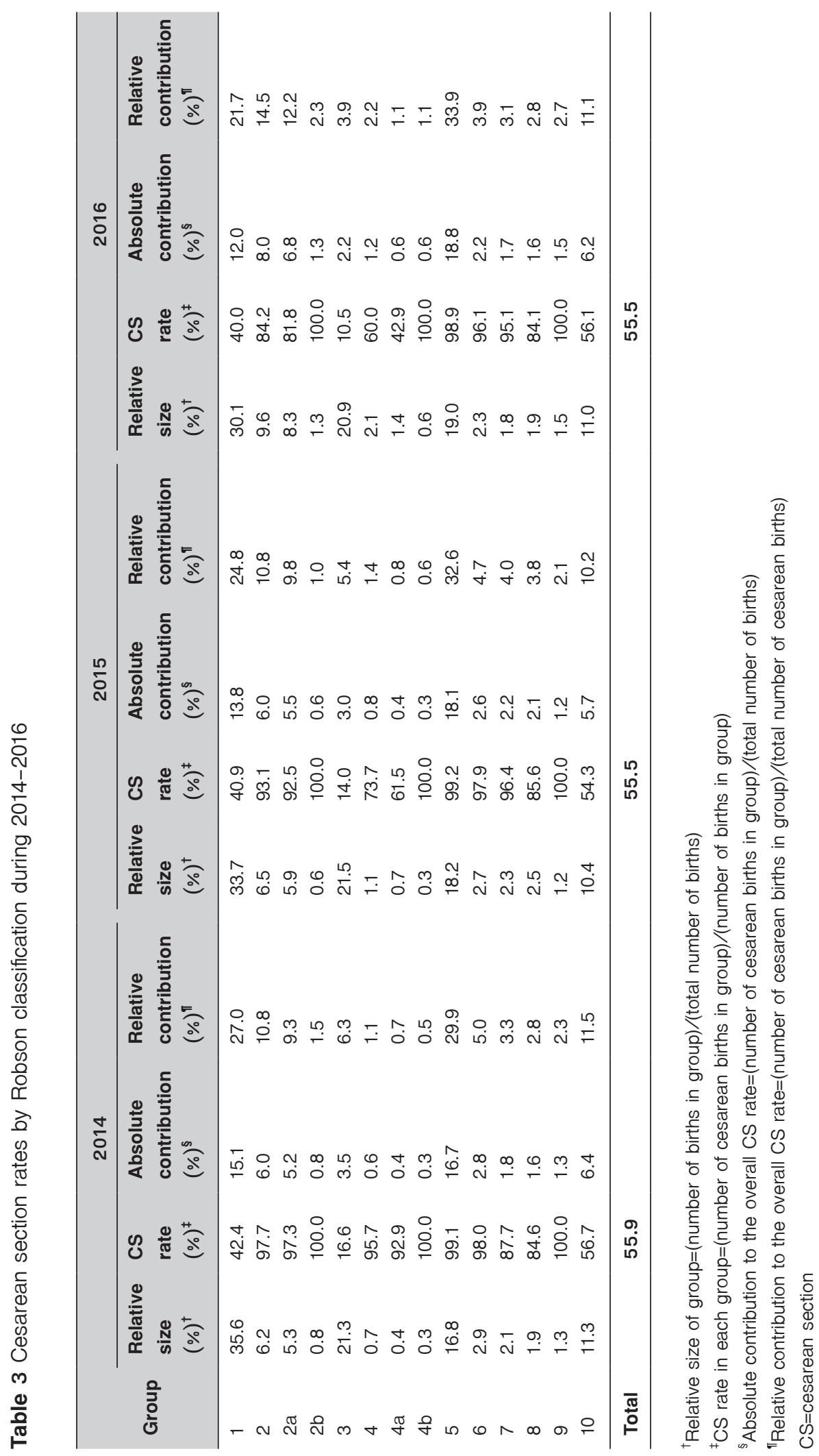



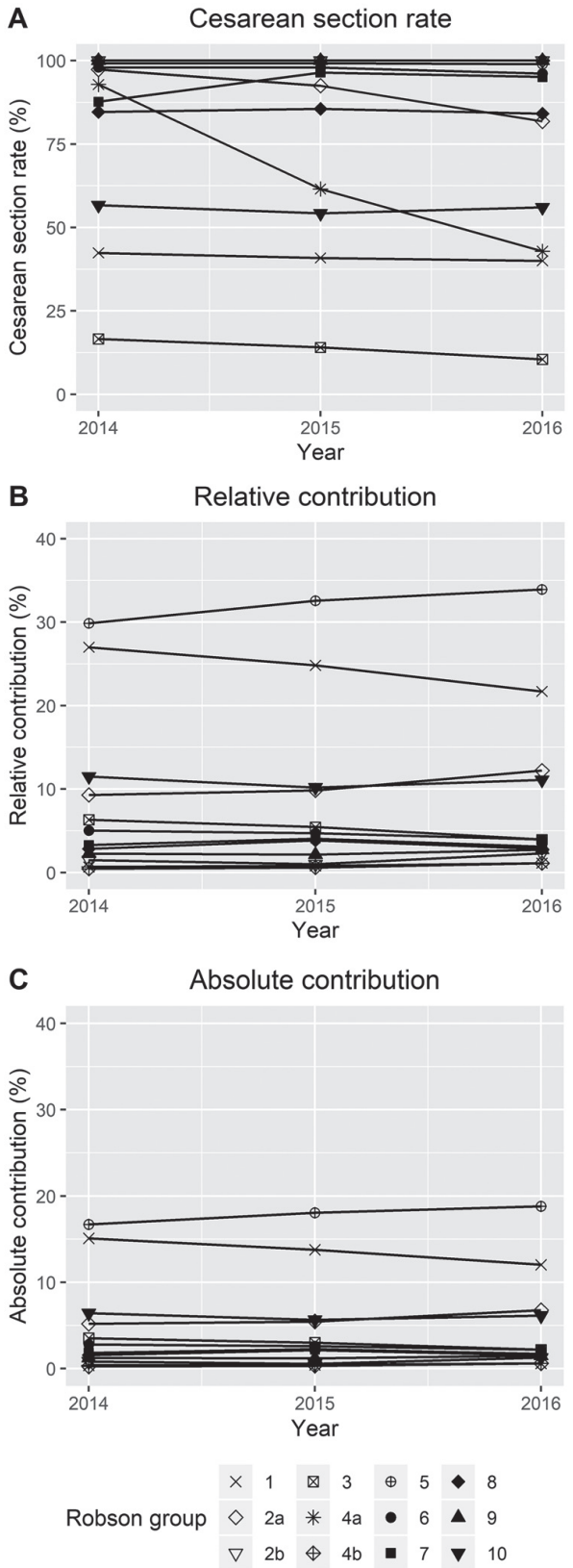

Figure 2 Trends of cesarean section stratified by Robson classification during 2014-2016

(A: Cesarean section rate in each group, B: Relative contribution of each group to the overall cesarean section rate, C: Absolute contribution of each group to the overall cesarean section rate.) group 1 (21.7\% and $12.0 \%$, respectively), group 2 (14.5\% and $8.0 \%$, respectively) and group $10(11.1 \%$ and $6.2 \%$, respectively). Figure 2 shows the trends of CS stratified by Robson classification during 2014-2016. The CS rates in each group were relatively static during these years, except the CS rates in groups $4 \mathrm{a}$ and $2 \mathrm{a}$ which were dramatically reduced ( $p$-value for trend $<0.001$ ), those in group 3 which were slightly reduced and those in group 7 which were slightly increased ( $p$-value for trends <0.05) (Figure 2A). The relative and absolute contributions of each group to the overall CS rates were relatively static in almost all groups. Slightly reduced contributions to the overall CS rates were observed in group 1 (Figures $2 A-C$ ) and slightly increased contributions were observed in group 5 (Figures 2B-C).

The CS rates according to the Robson classification in public and private services are shown in Table 4. Compared to women using private service, higher proportions of women in groups $3,4 \mathrm{~b}$, and 10 , but lower proportions of women in groups $1,2 \mathrm{a}$, and 5 in public service, were found. The overall CS rates in women using private service were slightly higher than those using public service $(58.6 \%$ and $51.6 \%$, respectively). The CS rates between both services were similar in most groups, except for a higher CS rate in group 3 and a lower CS rate in group 8 in public service. The relative and absolute contributions of each group to the overall CS rates were significantly different in most groups, except in groups $2 \mathrm{~b}, 4 \mathrm{a}, 6,8$, and 9.

The indications for CS in groups 1-4 are presented in Figure 3. For women having induction of labor (groups 2a and $4 \mathrm{a}$ ), more than half had CS due to failed induction, which was higher in nulliparous $(62.1 \%$ in 2016$)$ than multiparous $(50.0 \%$ in 2016) women. For women undergoing CS before labor (groups $2 \mathrm{~b}$ and $4 \mathrm{~b}$ ), the most common indication was placenta previa $(27.9 \%$ in nulliparous and 


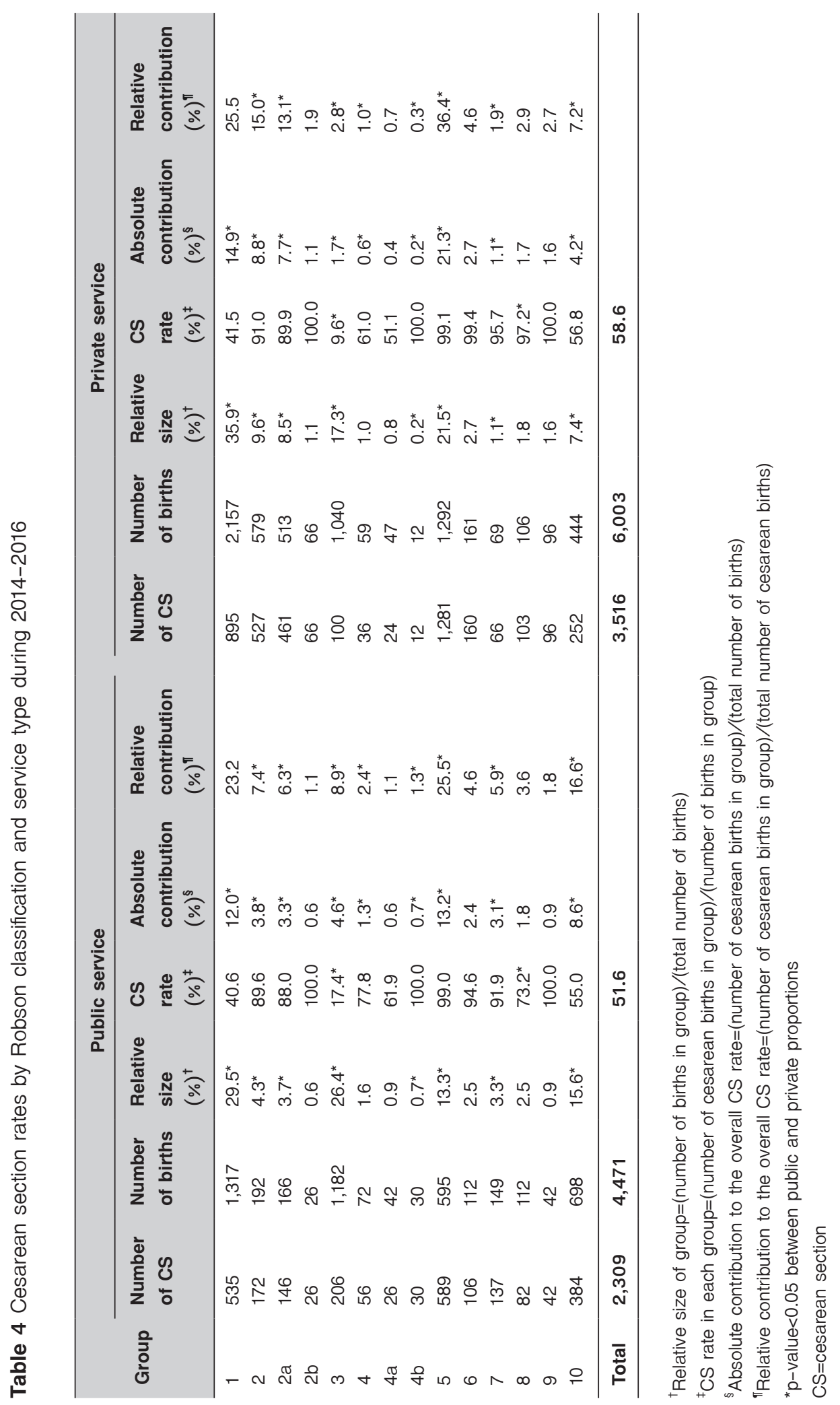


$40.9 \%$ in multiparous women) followed by fetal distress in 2016. Cephalopelvic disproportion (CPD) and fetal distress were the most common indications in group 1 (44.9\% and $38.7 \%$, respectively, in 2016) and group $3(48.6 \%$ and
$39.2 \%$, respectively, in 2016). The three main indications for CS in group 10 were previous CS, fetal distress and pregnancy-induced hypertension $(\mathrm{PIH})$ (data not shown).
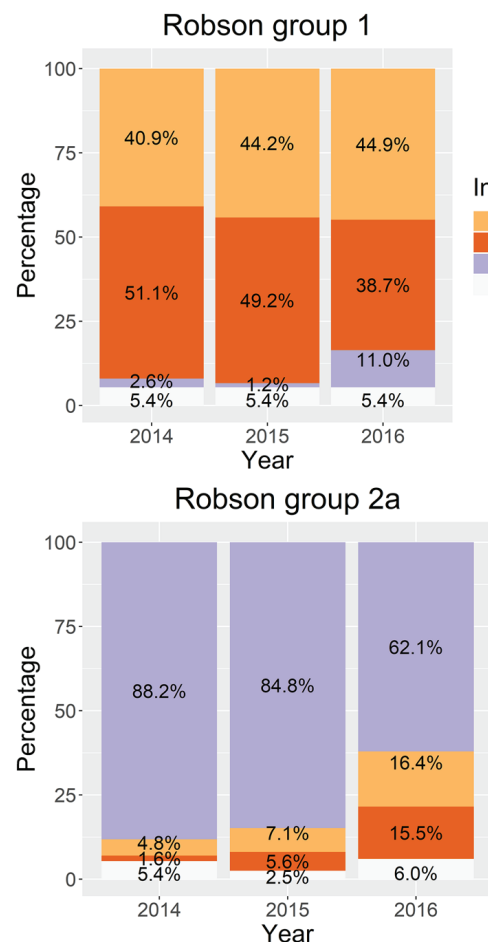

Robson group $2 b$

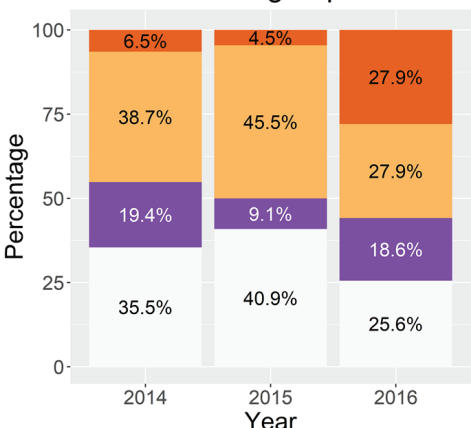

Robson group 3

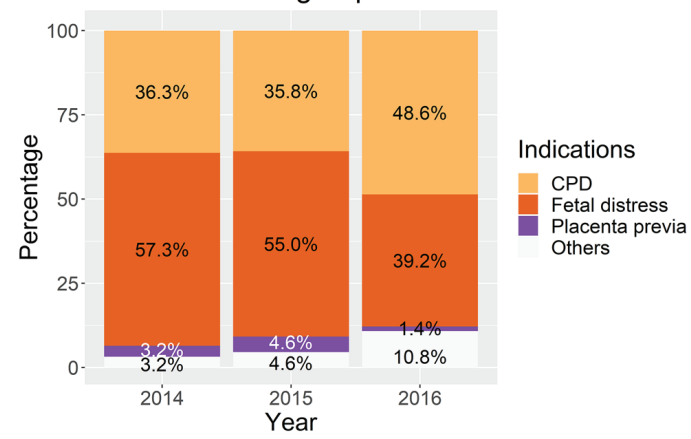

Robson group $4 a$

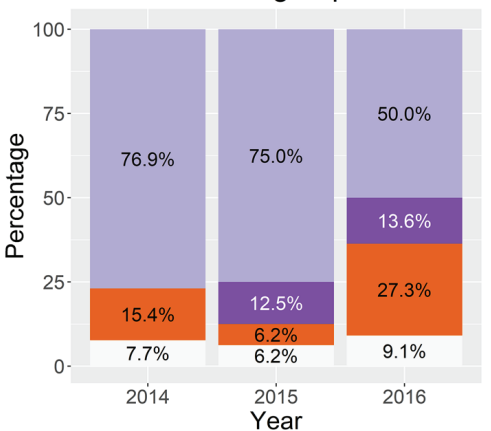

Robson group 4b

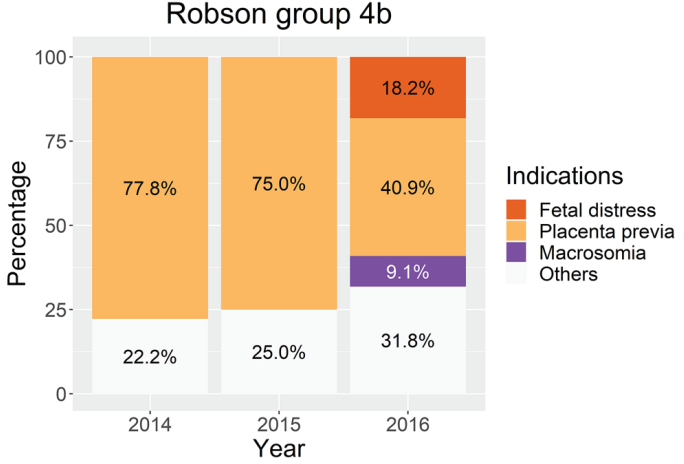

$\mathrm{CPD}=$ cephalopelvic disproportion, $\mathrm{PIH}=$ pregnancy-induced hypertension

Figure 3 Indications for cesarean section in groups 1-4 during 2014-2016 


\section{Discussion}

Approximately half of the pregnant women in the study underwent CS during 2014-2016. The trends of the CS rates over the 3 years in most Robson classification categories were relatively stable, except in groups $2 a$ and $4 \mathrm{a}$ which were notably reduced over the 3-year period, and among multiparous women with fetal breech presentation (group 7), which slightly increased over the 3-year period. The highest relative contribution and absolute contribution were found in women with previous CS (group 5) and nulliparous women with spontaneous labor (group 1). Cephalopelvic disproportion and fetal distress were the most common indications for CS in nulliparous and multiparous women with spontaneous labor.

For all births, the largest proportion of women undergoing CS was observed in group 1, followed by group 3, a finding similar to studies at university hospitals in Australia, Brazil, and Thailand $d^{11,18,19}$ as well as studies from public hospitals in Thailand. ${ }^{10,12}$ In some studies, the largest proportion was reported in group 3 rather than group $1 .^{20-22}$ This inverse finding can be explained by noting that a nulliparous woman who underwent CS would be then classified in group 5, not group 3 , in a subsequent pregnancy.

The overall CS rates in our study were higher than the recommended $\mathrm{WHO}$ rates in all three years of the study. ${ }^{1}$ The women in groups 1 and 3, who were term, cephalic, singleton pregnancies with spontaneous labor, are defined as low-risk pregnancies for which the WHO recommends that the CS rates should not be higher than $10.0 \%$ in group 1 and $3.0 \%$ in group $3 .{ }^{17}$ In our study, the CS rates in groups 1 and 3 were $40.0 \%$ and $10.5 \%$, respectively, which were notably higher than the $\mathrm{WHO}$ recommendation and the rates reported in other studies from university hospitals in Australia, Brazil, Egypt, Italy, Singapore, Tanzania, and Thailand..$^{11,18-23}$ In our study, the most common indications for CS in groups 1 and 3 were cephalopelvic disproportion and fetal distress, which is consistent with the results of previous studies. ${ }^{11,20,24}$ These indications for CS were recognized before the recommendations of the Robson classification. ${ }^{25}$ To reduce CS rates, a clinical practice guideline for CS due to cephalopelvic disproportion was implemented in our hospital in 1999, however, this guideline was not effective in reducing this CS rate. ${ }^{15,26}$ This could be due to different practices among individual obstetricians, a situation which requires a future intensive study to explore the indications of cephalopelvic disproportion and fetal distress indicating CS. In addition, the information gleaned from the system using Robson classifications could be useful in devising policies to reduce CS rates. Although indications for CS are not examined in the Robson classifications, it may be useful as a root cause of future development of preventive measures.

Significant reductions in CS rates among the women in groups $2 \mathrm{a}$ and $4 \mathrm{a}$ during the 3 -year period were observed in our study. Although the obstetricians at our hospital have been following the WHO guidelines on induction of labor since the these guidelines were released in $2011^{27}$, the CS rates in these group in our study were still higher than those reported in previous studies in Thailand, while the relative contribution to overall CS rates were lower, which could be due to the lower ratio of group 1 to group 2 in our study. ${ }^{10,11}$ Previous studies have found substantial increases in CS rates due to falling of the clinical threshold for CS after induction, or increasing use of elective induction. ${ }^{21-23}$ A study involving countries in Africa and Asia found that the elective induction rates were high but its success rate was relatively low in Thailand compared to these countries ${ }^{28}$, thus it was not surprising that failed induction was the most common indication for CS in groups $2 \mathrm{a}$ and $4 \mathrm{a}$. The rate of failed induction in our study would not have been as high if our guidelines for labor induction with appropriate indications had been followed. In our study, the CS rate among women with fetal 
breech presentation in group 7 was high in all 3 years, with a slight increase over the 3 -year period. This is because a scheduled CS is recommended for a woman with breech fetal presentation detected during antenatal care visit in our setting that was similar to the finding of a previous study conducted in another university hospital in Thailand. ${ }^{11}$ A study in Tanzania reported similar findings ${ }^{23}$, while studies from Italy and Singapore reported stable trends in this group. ${ }^{21,22}$ One study reported evidence that a planned CS in breech presentations had lower short-term perinatal mortality and morbidity compared with planned vaginal birth. $^{29}$ The best mode of birth in women with breech fetal presentation is still controversial because of unclear long-term benefits and risks of maternal mortality and morbidity associated with planned cesarean birth., 4,29,30

Women with previous CS (group 5) were the main contributor to the overall CS rate, followed by groups 1 and 2, which studies from university hospitals in Australia, Brazil, Egypt, Italy, Singapore, Tanzania, and Thailand also found. ${ }^{11,18-23}$ Our findings concerning this point were higher than the findings from a similar study in another province in Thailand ${ }^{10}$, which we attribute to different study designs and settings. Vaginal birth after a previous cesarean birth (VBAC) should be offered in appropriate cases to reduce the elective CS rate in women with previous CS. Although VBAC is safe and appropriate for most women with previous $\mathrm{CS}^{31}$, VBAC is not performed in our hospital due to limitations of medical personnel and resources. ${ }^{15}$ We would suggest that the most effective way to reduce the CS rate in group 5 would be to reduce the rate of the first CS procedure in nulliparous women (groups 1 and 2), which would reduce the number of women with previous CS in the future.

The overall CS rates in our study were slightly higher in private service than in public service, resulting from higher relative and absolute contributions of groups 2a and 5. Previous studies in Brazil and Thailand also found that women in public service had more than twofold higher CS rate than women in public service. ${ }^{32,33}$ The higher relative and absolute contributions of group 5 in private service reflect high primary CS rates in the past few years. Therefore, policies for auditing CS should focus on private service as well because in private service the decision to deliver by CS is made be a single obstetrician.

There are to date few studies on the Robson classification system from Thailand. Our study presents the CS rates by Robson classification for three years with accurate data from the Statistical Unit of the Department of Obstetrics and Gynecology database, which has been collecting and auditing obstetrical data from the largest medical referral center in southern Thailand for three decades. There are some potential limitations to this study. We used data from three consecutive years to estimate the trend of CS rates. However, ten points of observation are usually required to provide the best statistical power of estimated trends ${ }^{34}$; to compensate for this problem, we divided the annual data into quarters, which gave us 12 points of observation (data not shown). Another limitation is that no other variables that might be related to CS rates were analyzed.

\section{Conclusion}

The CS rates in our setting were high in all Robson classification groups and static in most groups during the 3-year study period. Nulliparous women with spontaneous labor and those having previous CS should be the target groups for reducing CS since these groups were the highest contributors to the overall CS rate in our study. Categorizing pregnant women into the Robson classifications is feasible and realistic for monitoring CS rates. Feedback of the Robson classification findings to relevant health care providers and policy makers is required. Integrating information for the Robson classification into existing hospital information systems will be useful for 
applying the Robson classification system in the future. Monitoring CS rates using Robson classification in the process of internal and/or external audits and feedback is required to be studied for optimizing the CS rates in each Robson group.

\section{Acknowledgement}

The authors acknowledge the assistance of the Statistical Unit of the Department of Obstetrics and Gynecology in making their database available for data analysis.

\section{Funding sources}

This study was supported by a grant from the Faculty of Medicine, Prince of Songkla University.

\section{Conflict of interest}

All authors report no conflicts of interest.

\section{References}

1. World Health Organization. Appropriate technology for birth. Lancet 1985;2:436-7.

2. Vogel JP, Betrán AP, Vindevoghel N, Souza JP, Torloni MR, Zhang $\mathrm{J}$, et al. Use of the Robson classification to assess caesarean section trends in 21 countries: a secondary analysis of two WHO multicountry surveys. Lancet Glob Health 2015; 3:e260-70

3. Ye J, Zhang J, Mikolajczyk R, Torloni M, Gülmezoglu A, Betran A. Association between rates of caesarean section and maternal and neonatal mortality in the 21st century: a worldwide population-based ecological study with longitudinal data. BJOG 2016;123:745-53.

4. Lumbiganon $P$, Laopaiboon M, Gülmezoglu AM, Souza JP, Taneepanichskul S, Ruyan P, et al. Method of delivery and pregnancy outcomes in Asia: the WHO global survey on maternal and perinatal health 2007-08. Lancet 2010;375: 490-9.

5. Allen VM, O'Connell CM, Farrell SA, Baskett TF. Economic implications of method of delivery. Am J Obstet Gynecol 2005;193:192-7.
6. Torloni MR, Betran AP, Souza JP, Widmer M, Allen T, Gulmezoglu M, et al. Classifications for cesarean section: a systematic review. PLoS One 2011;6. doi: 10.1371/journal. pone.0014566.

7. Robson MS. Classification of caesarean sections. Fetal Matern Med Rev 2001;12:23-39.

8. Betran A, Torloni M, Zhang J, Gülmezoglu A, WHO working group on caesarean section. WHO statement on caesarean section rates. BJOG 2016;123:667-70.

9. Betrán AP, Vindevoghel N, Souza JP, Gülmezoglu AM, Torloni MR. A systematic review of the Robson classification for caesarean section: what works, doesn't work and how to improve it. PLoS One 2014;9. doi: 10.1371/journal.pone. 0097769.

10. Kankoon N, Lumbiganon P, Kietpeerakool C, Sangkomkamhang U, Betrán AP, Robson M. Cesarean rates and severe maternal and neonatal outcomes according to the Robson 10-group classification system in Khon Kaen province, Thailand. Obstet Gynecol Int J 2018;140:191-7.

11. Anekpornwattana S, Yangnoi J, Jareemit N, Borriboonhiransan D. Cesarean section rate in Siriraj hospital according to the Robson classification. Thai J Obstet Gynecol 2020;28:6-15.

12. Khornwong S, Kovavisarach E. Cesarean section rate based on the Robson 10-group classification at Rajavithi hospital from 2015-2018. Thai J Obstet Gynecol 2020;28. [In press].

13. Committee on Obstetric Practice, American Institute of Ultrasound in Medicine, Society for Maternal-Fetal Medicine. Committee opinion no 700: methods for estimating the due date. Obstet Gynecol 2017;129:e150-4.

14. Baños N, Migliorelli F, Posadas E, Ferreri J, Palacio M. Definition of failed induction of labor and its predictive factors: two unsolved issues of an everyday clinical situation. Fetal Diagn Ther 2015;38:161-9.

15. Suwanrath-Kengpol C, Pinjaroen S, Krisanapan K, Petmanee $P$. Effect of a clinical practice guideline on physician compliance. Int J Qual Health Care 2004;16:327-32.

16. World Health Organization. International statistical classification of diseases and related health problems 10th revision [homepage on the Internet]. Geneva: WHO; 2016 [cited 2020 Apr 7]. Available from: https://icd.who.int/browse10/ 2016/en

17. World Health Organization. Robson classification: implementation manual [homepage on the Internet]. Geneva: WHO; 2017 [cited 2018 Nov 27]. Available from: http://www.who. 
int/reproductivehealth/publications/maternal_perinatal_health/ robson-classification/en/

18. Ferreira EC, Pacagnella RC, Costa ML, Cecatti JG. The Robson ten-group classification system for appraising deliveries at a tertiary referral hospital in Brazil. Obstet Gynecol Int J 2015;129:236-9.

19. McCarthy FP, Rigg L, Cady L, Cullinane F. A new way of looking at caesarean section births. Aust N Z J Obstet Gynaecol 2007;47:316-20.

20. Abdel-Aleem H, Shaaban OM, Hassanin Al, Ibraheem AA Analysis of cesarean delivery at Assiut university hospital using the ten group classification system. Int J Gynecol Obstet 2013;123:119-23.

21. Triunfo S, Ferrazzani S, Lanzone A, Scambia G. Identification of obstetric targets for reducing cesarean section rate using the Robson ten group classification in a tertiary level hospital. Eur J Obstet Gynecol Reprod Biol 2015;189:91-5.

22. Chong C, Su LL, Biswas A. Changing trends of cesarean section births by the Robson ten group classification in a tertiary teaching hospital: cesarean section trends by Robson classes. Acta Obstet Gynecol Scand 2012;91:1422-7.

23. Litorp H, Kidanto HL, Nystrom L, Darj E, Essén B. Increasing caesarean section rates among low-risk groups: a panel study classifying deliveries according to Robson at a university hospital in Tanzania. BMC Pregnancy Childbirth 2013;13:107.

24. Tura AK, Pijpers O, de Man M, Cleveringa M, Koopmans I, Gure T, et al. Analysis of caesarean sections using Robson 10-group classification system in a university hospital in eastern Ethiopia: a cross-sectional study. BMJ Open 2018;8. doi: 10.1136/omjopen-2017-020520.

25. Charoenboon C, Srisupundit K, Tongsong T. Rise in cesarean section rate over a 20-year period in a public sector hospital in northern Thailand. Arch Gynecol Obstet 2013;287:47-52.
26. Chittithavorn S, Pinjaroen S, Suwanrath C, Soonthornpun K. Clinical practice guideline for cesarean section due to cephalopelvic disproportion. J Med Assoc Thai 2006;89:73540

27. World Health Organization. WHO recommendations for induction of labour [monograph on the Internet]. Geneva: WHO; 2011 [cited 2019 Jan 1]. Available from: http://www. who.int/reproductivehealth/publications/maternal_perinatal_ health/9789241501156/en/

28. Vogel JP, Souza JP, Gülmezoglu AM. Patterns and outcomes of induction of labour in Africa and Asia: a secondary analysis of the WHO global survey on maternal and neonatal health. PLoS One 2013;8. doi: 10.1371/journal.pone.0065612.

29. Hofmeyr GJ, Hannah M, Lawrie TA. Planned caesarean section for term breech delivery. Cochrane Database Syst Rev 2015; CD000166

30. ACOG committee opinion no. 745: mode of term singleton breech delivery. Obstet Gynecol 2018;132:e60-3.

31. Committee on Practice Bulletins-Obstetrics. Practice bulletin no.184: vaginal birth after cesarean delivery. Obstet Gynecol 2017;130:e217-33.

32. Nakamura-Pereira M, do Carmo Leal M, Esteves-Pereira AP, Domingues RMSM, Torres JA, Dias MAB, et al. Use of Robson classification to assess cesarean section rate in Brazil: the role of source of payment for childbirth. Reprod Health 2016;13:128.

33. Phadungkiatwattana $\mathrm{P}$, Tongsakul N. Analyzing the impact of private service on the cesarean section rate in public hospital Thailand. Arch Gynecol Obstet 2011;284:1375-9.

34. White ER. Minimum time required to detect population trends: the need for long-term monitoring programs. BioScience 2018;69:40-6. 